Original article

\title{
A survey of breast cancer physicians regarding patient involvement in breast cancer treatment decisions
}

\author{
Grace Clarke Hillyer ${ }^{a}{ }^{a}$, Dawn L. Hershman ${ }^{\text {a,b,c }}$, Lawrence H. Kushi ${ }^{\mathrm{d}}$, Lois Lamerato ${ }^{\mathrm{e}}$, \\ Christine B. Ambrosone ${ }^{\mathrm{f}}$, Dana H. Bovbjerg ${ }^{\mathrm{g}, \mathrm{h}}$, Jeanne S. Mandelblatt ${ }^{\mathrm{i}}$, Sargam Rana ${ }^{\mathrm{b}}$, \\ Alfred I. Neugut ${ }^{\mathrm{a}, \mathrm{b}, \mathrm{c}}$ \\ ${ }^{a}$ Department of Epidemiology, Mailman School of Public Health, Columbia University, 722 W. 168th Street, New York, NY 10032, United States \\ ${ }^{\mathrm{b}}$ Department of Medicine, College of Physicians and Surgeons, New York, NY, United States \\ ${ }^{\mathrm{c}}$ Herbert Irving Comprehensive Cancer Center, College of Physicians and Surgeons, New York, NY, United States \\ ${ }^{\mathrm{d}}$ Division of Research, Kaiser-Permanente of Northern California, Oakland, CA, United States \\ ${ }^{\mathrm{e}}$ Department of Public Health Sciences, Henry Ford Health System, Detroit, MI, United States \\ ${ }^{\mathrm{f}}$ Department of Cancer Prevention and Control, Roswell Park Cancer Institute, Buffalo, NY, United States \\ ${ }^{\mathrm{g}}$ Department of Psychiatry, Psychology and Behavioral \& Community Health Sciences, University of Pittsburgh, Pittsburgh, PA, United States \\ ${ }^{\mathrm{h}}$ University of Pittsburgh Cancer Institute, Pittsburgh, PA, United States \\ ${ }^{\mathrm{i}}$ Department of Oncology and Lombardi Comprehensive Cancer Center, Georgetown University Medical Center, Washington, DC, United States
}

\section{A R T I C L E I N F O}

\section{Article history:}

Received 3 July 2012

Received in revised form

2 October 2012

Accepted 3 October 2012

\section{Keywords:}

Breast cancer

Treatment decision-making

Physician survey

Patient participation

\begin{abstract}
A B S T R A C T
Purpose: Shared breast cancer treatment decision-making between patients and physicians increases patient treatment satisfaction and compliance and is influenced by physician-related factors. Attitudes and behaviors about patient involvement in breast cancer treatment decisions and treatment-related communication were assessed by specialty among breast cancer physicians of women enrolled in the Breast Cancer Quality of Care Study (BQUAL).

Results: Of 275 BQUAL physicians identified, $50.0 \%$ responded to the survey. Most physicians spend 46-60 min with the patient during the initial consult visit and 51.5\% report that the treatment decision is made in one visit. Oncologists spend more time with new breast cancer patients during the initial consult $(p=0.021)$, and find it more difficult to handle their own feelings than breast surgeons $(p=<0.001)$.

Conclusion: Breast surgeons and oncologists share similar attitudes and behaviors related to patient involvement in treatment decision-making, yet oncologists report more difficulty managing their own feelings during the decision-making process.
\end{abstract}

(c) 2012 Elsevier Ltd. All rights reserved.

\section{Introduction}

Significant improvements in survival of breast cancer that have been achieved in the past several decades have been attributed to early detection and the widespread use of adjuvant therapy. ${ }^{1}$ The use of biomarkers for the human epidermal growth factor receptor 2 (HER2), quantification of estrogen/progesterone receptors, and identification of genetic markers as prognostic and predictive tools enable clinicians to customize treatment to maximize benefits and improve outcomes for patients. ${ }^{2,3}$ In cases where more than one treatment option is acceptable, ${ }^{4}$ the patient's involvement in the treatment decision and her preference for one treatment over another and/or avoidance of side effects over another is crucial.

\footnotetext{
* Corresponding author. Tel.: +1 212342 1658; fax: +1 2123426802 .

E-mail address: gah28@columbia.edu (G.C. Hillyer).
}

Evidence suggests that women who are engaged in the treatment decision-making process to the extent with which they are most comfortable are more likely to comply with treatment, report increased satisfaction with the treatment and experience better quality of life. $^{5-7}$

Over the course of breast cancer care, a woman typically engages in discussions for primary treatment with a breast surgeon and, quite often, with oncologists (medical and radiation) for adjuvant treatment. In her encounters with each physician along the breast cancer care continuum, a vast amount of specialized information is communicated, along with a spectrum of treatment options and alternatives - all requiring consideration and a decision to be made.

We examined attitudes and behaviors related to patient involvement in treatment decision-making and patient-physician communication attitudes among oncologists and breast surgeons, 
by specialty. Elucidation of physician-related factors with the potential to influence the treatment decision process and, thus the receipt of optimal breast cancer care may provide opportunities for future interventions to increase uptake of life-saving treatments.

\section{Materials and methods}

Participantsincludedoncologistsandbreastsurgeonsinvolvedinthe breastcancertreatmentofwomenenrolledintheBreastCancerQualityof Care(BQUAL)Study,amulticenterlongitudinalstudyof 1157earlystage breast cancer patients. A full description of the methods has been reportedelsewhere. ${ }^{8}$ Tosummarize, womenwhowerenewlydiagnosed withprimary,histologicallyconfirmedbreastcancer(stagesI-III)were enrolledbetween2006and2010fromthreerecruitmentsites(Columbia University Medical Center and Mount Sinai School of Medicine in New YorkCity,HenryFordHealthSystemofmetropolitanDetroitandKaiserPermanenteofNorthernCalifornia).Womencompletedaseriesofthree surveys administered over the telephone at 3,4, and 8 months postdiagnosis.Duringeachsurvey,subjectswereaskedtoprovidethename andaddressofthesurgeonwhoperformedtheirdefinitivebreastcancer surgeryandtheoncologist(bothmedicalandradiation)overseeingtheir care and adjuvant treatment, when applicable. Physician information was verified by the research investigator at each recruitment site and emailaddresseswereobtained.

Physicians were sent a study invitation via email and a secure, personalized link to the SurveyMonkey ${ }^{\mathrm{TM}}$ website between July 2009 and July 2010. A cover letter informed the physician how he/ she was selected for this study without revealing the identity of the BQUAL study patient who had supplied their name. An incentive (\$50 gift card) for the completion and return of the survey was offered. In the event of a non-viable email address, surveys were sent via U.S. Postal Mail Service in the same manner as the electronic surveys. All procedures and a waiver of written informed consent were approved by the Institutional Review Board of each recruitment site, the U.S. Army Medical Research and Materiel Command Office of Research Protection and Human Research Protection Office.

The survey was comprised of two sections: the first gathered information related to physician demographics, practice characteristics, and patient population characteristics, and the second assessed physician attitudes and behaviors related to breast cancer treatment decisions and treatment-related patient-physician communication barriers. Demographics included physician specialty (oncologist vs. breast surgeon), gender, age, race (White, Asian, other race), nativity (U.S. born vs. non-U.S.), years of experience, recruitment site of BQUAL participant (New York, Northern California, or metropolitan Detroit), country where attended medical school (U.S. vs. non-U.S.), and specialty board certification. Practice characteristics consisted of practice type (private vs. other), and teaching hospital, NCI-designated cancer center affiliation, percent of patients being evaluated, treated or followed for breast cancer, new breast cancer patients in the past 6 months, and new patients per week. For patient population characteristics, race/ ethnicity (White, black/African American, Hispanic, Asian, and other race), insurance coverage (Medicare, private insurance, Medicaid, none or other), and primary patient population language other than English (Spanish vs. other) was assessed.

Factors surrounding the treatment decision-making process that were examined were length of the initial consult visit in minutes, number of visits needed in order to make a treatment plan decision, and the percent of patients enrolled into clinical trials. To evaluate attitudes toward patient involvement in the treatment decision-making process, a measure developed by Liberati et al. ${ }^{9}$ was used in which respondents were asked to indicate on a 5-point Likert scale the extent to which they agreed or disagreed with a series of 10 statements, such as "encouraging patient to participate [in treatment decisions] may do more harm than good" or "patients who participate in treatment decisions make a better adjustment to the disease". Five negatively worded statements were reverse coded; thus, higher scores indicated more favorable attitudes toward patient involvement in treatment decisions whereas lower scores indicated less favorable attitudes.

The measure of treatment communication behaviors was adapted from Braddock et al. ${ }^{10}$ Respondents were queried about 10 separate communication components that would provide patients with information sufficient to make an informed treatment decision. Examples include discussing the patient's role in the decisionmaking process, explaining the potential risks and benefits of treatment and alternatives to treatment, and asking the patient her opinion about her treatment options. Responses were coded as "yes or no". To examine barriers surrounding the communication of treatment information to patients, respondents were asked about perceived difficulty in dealing with the patient's family, responding to the patient's needs, being honest without depressing the patient, handling personal negative feelings, not disclosing poor prognosis at the request of the family, and giving specific probabilities of the treatment not working based on the work of Baile et al. ${ }^{11}$ Responses ranged from "not difficult at all" to "very difficult" and were later dichotomized as "difficult/not difficult".

Descriptive analyses included frequency distributions for categorical variables and mean and standard deviation for continuous variables. Using Chi-square analysis and Student's $t$ with a twosided $\alpha=0.05$, we compared physician, practice and patient population characteristics and treatment-related attitudes and behaviors by physician specialty. Results were considered significant using $p \leq 0.05$. All analyses were conducted using IBM SPSS Statistics version 19 .

\section{Results}

Overall, 1157 women with newly diagnosed primary, invasive breast cancer were enrolled to the BQUAL study for whom a total of 275 treating physicians were identified. Of these physicians, 137 were medical oncologists (49.8\%) and 138 (50.2\%) breast surgeons. One hundred thirty eight physicians (47.8\% oncologists, $52.2 \%$ breast surgeons) responded to the survey, for a response rate of $50.0 \%$, representing $80 \%(921 / 1157)$ of BQUAL study participants. There was no statistically significant difference between physician responders and non-responders by specialty or recruitment site.

Fig. 1 shows the distribution of treating physicians by site (New York City, Northern California, and metropolitan Detroit) and specialty (oncologist vs. breast surgeon) identified by the BQUAL participants. Women recruited from Northern California more often identified breast surgeons (57.0\% vs. $43.0 \%$ ) as their treating physician compared to New York City and the metropolitan Detroit area, where participants more often reported receiving their care from oncologists ( $p=0.008$ ) (Fig. 1).

Respondents were predominantly White (67.4\%), U.S. born (72.5\%) males (63.0\%) between the ages of 40 and 59 years $(34.6 \%)$ (Table 1$)$. Most were engaged in private practice $(65.4 \%$ vs. $34.6 \%$ other practice type), and affiliated with a teaching hospital (69.9\%). Compared to oncologists in our sample, breast surgeons were more likely to be U.S. born ( $80.6 \%$ vs. $63.6 \%, p=0.03)$ and to have attended a non-U.S. medical school $(94.4 \%$ vs. $75.4 \%, p=0.002)$. Practice and patient population characteristics varied between oncologists and surgeons in terms of the number of breast cancer patients seen in the past 6 months, the number of new patients seen on a weekly basis, and the insurance coverage of their respective patient populations. Oncologists more often reported evaluating, treating and following a larger proportion of their 


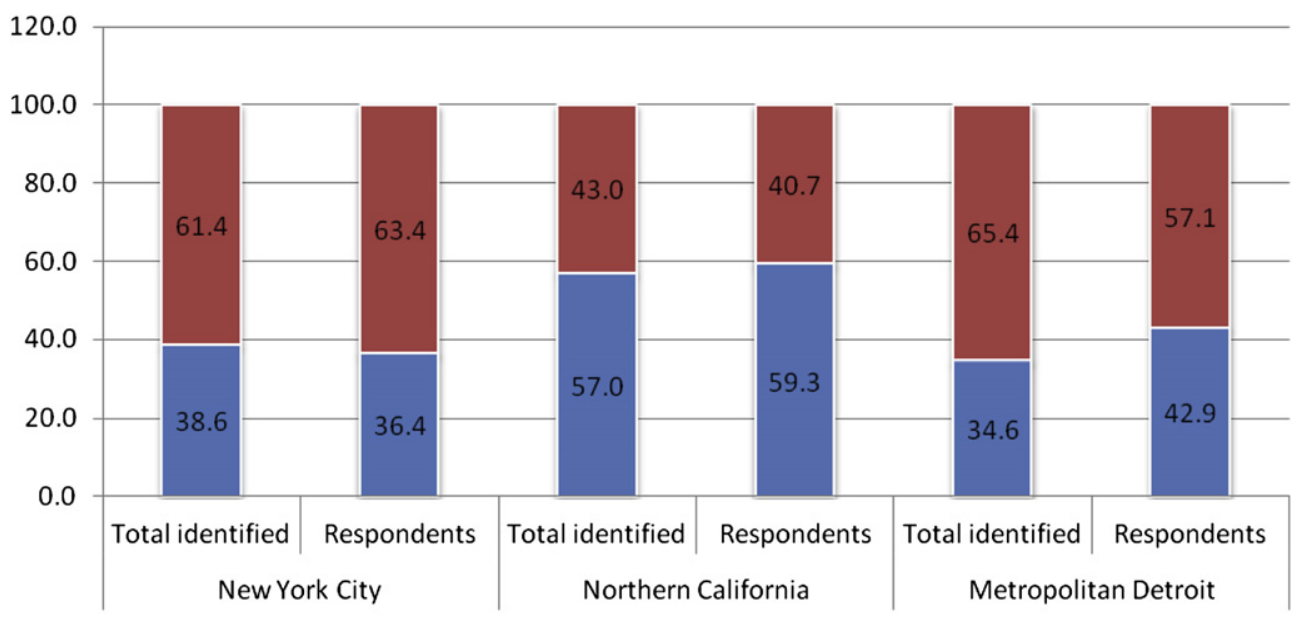

m Breast surgeon $\quad$ Oncologist

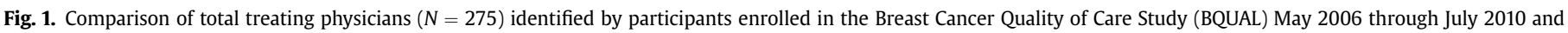
physicians respondents $(N=138)$ by recruitment site and specialty (oncologist, $N=66$ vs. breast surgeon, $N=72$ ).

patient population ( $40.6 \%$ vs. $29.4 \%, p=0.015$ ) and having a larger proportion of their practice comprised of patients diagnosed in the past 6 months with breast cancer $(39.1 \%$ vs. $20.9 \%, p=<0.001)$ compared to surgeons. Conversely, surgeons reported a new patient load more than twice that of oncologists (19.5\% vs. $7.2 \%$, $p=<0.001)$. The majority of patients treated by our respondents were White (51.9\%) and privately insured (49.3\%). Oncologists reported that one-third of their patients were Medicare insured as opposed to $18.9 \%$ for surgeons ( $p=<0.001$ ) whereas surgeons reported significantly more patients with other types of insurance (21.8\% vs. $4.9 \%, p=0.002)$ than did oncologists.

Physicians' behaviors and attitudes toward breast cancer treatment decision-making are displayed in Table 2. More than onethird $(38.3 \%)$ of physicians spend $46-60 \mathrm{~min}$ with the patient during the initial consult visit. Approximately half of the respondents stated that a single visit is needed to come to a treatment decision and $68.9 \%$ reported enrolling $\leq 10 \%$ of their breast cancer patients into clinical trials. Overall, respondents preferred a less patient-oriented approach toward treatment decision-making (53.8\% vs. $46.2 \%$ more patient-oriented) but engaged in communication that explored the patient's treatment preference and asked for her opinion about treatment options discussed (97.0\%). Nearly all respondents reported providing clear statements to their patients of the importance of the treatment decision (96.2\%), discussing alternatives to treatment and explaining risks and benefits of treatment (97.7\%). Fewer, though a substantial number, encourage women to involve their family members and significant others in the treatment decision (84.1\%). Comparing physicians' attitudes and behaviors related to treatment decisions by specialty showed that oncologists in our sample spend more time with new breast cancer patients during the initial consult ( $p=0.021$ ), have more difficulty dealing with the patient's family ( $60.6 \%$ vs. $43.9 \%, p=0.055$ ), tend to find it more difficult to be honest with the patient without depressing her (59.1\% vs. $42.4 \%$, $p=0.055$ ), and find it more difficult to handle their own feelings with regard to patient treatment decisions $(60.6 \%$ vs. $25.8 \%$, $p=<0.001$ ) than do breast surgeons.

In separate analyses we explored the influence of select physician characteristics (gender and age), practice characteristics (type, affiliation with an $\mathrm{NCI}$ cancer center or teaching hospital and site) and patient population composition (race and insurance coverage) on physician's attitudes and behaviors. We found no significant associations between these factors and whether a physician preferred a patient-oriented approach over a paternalistic one. Further, we found that patient population characteristics did not influence physician attitudes and behaviors toward treatment decisions.

With regard to treatment communication behaviors, male physicians more often reported not discussing the patient's role in treatment decision-making ( $15.7 \%$ vs. $4.1 \%, p=0.04)$. All older physicians ( $\geq 50$ years) reported discussing alternatives to each treatment, including doing nothing at all, with their patients as opposed to $93.2 \%$ of younger physicians ( $p=0.046$ ) but less often reported providing patients enough information to make decisions on their own (17.5\% vs. $5.5 \%$ younger, $p=0.028)$. Physicians in private practice $(4.8 \%$ vs. $17.4 \%$ in other types, $p=0.017)$, and respondents from the metropolitan Detroit area $(71.4 \%$ vs. New York with $87.9 \%$ and California with $94.0 \%, p=0.03$ ) less often talked to their patients about the uncertainties associated with each treatment. Affiliation with teaching hospital was associated with encouraging the patient to involve her family and significant others in the treatment decision more often compared to physicians in community hospitals ( $89.1 \%$ vs. $74.4 \%, p=0.03$ ). Affiliation with an NCI cancer center, however, had no effect on physician treatment decision-making attitudes.

When assessing barriers to treatment communication, we found that physicians affiliated with an NCI cancer center had less difficulty withholding a poor prognosis at the request of the family compared to those with no such affiliation ( $9.8 \%$ vs. $1.2 \%, p=0.02$ ). Male physicians found it less difficult to not disclose a poor prognosis if the patient did not ask $(20.7 \%$ vs. $6.4 \%, p=0.03)$ and found giving specific probabilities of the treatment not working less difficult ( $36.1 \%$ vs. $19.1 \%, p=0.04$ ) compared to female physicians.

\section{Discussion}

In this survey of attitudes and behaviors related to patient involvement in treatment making decisions among a group of physicians providing breast cancer care, we found few differences by physician specialty. Oncologists tend to spend more time during the initial consult and more often report struggling with their own emotions than do surgeons. These, however, may be a reflection of the relatively longer-term relationship a patient has with her oncologist and differences in the decisions being made such as 
Table 1

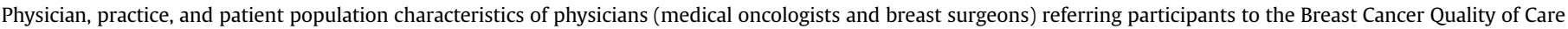
Study (BQUAL) $(N=138)$, May 2006 through July 2010

\begin{tabular}{|c|c|c|c|c|c|c|c|}
\hline & \multicolumn{2}{|c|}{ Total $N=138$} & \multicolumn{2}{|c|}{ Oncologist $N=66$} & \multicolumn{2}{|c|}{ Surgeon $N=72$} & \multirow[t]{2}{*}{$p$ Value } \\
\hline & $N$ & $\%$ & $N$ & $\%$ & $N$ & $\%$ & \\
\hline \multicolumn{8}{|l|}{ Physician characteristics } \\
\hline Gender & & & & & & & 0.40 \\
\hline Male & 87 & 63.0 & 44 & 66.7 & 43 & 59.7 & \\
\hline Female & 51 & 37.0 & 22 & 33.3 & 29 & 40.3 & \\
\hline Age & & & & & & & 0.95 \\
\hline $30-39$ & 31 & 22.8 & 16 & 24.6 & 15 & 21.1 & \\
\hline $40-49$ & 47 & 34.6 & 22 & 33.8 & 25 & 35.2 & \\
\hline $50-59$ & 40 & 29.4 & 18 & 27.7 & 22 & 31.0 & \\
\hline $60-69$ & 18 & 13.2 & 9 & 13.8 & 9 & 12.7 & \\
\hline Race/ethnicity & & & & & & & 0.09 \\
\hline White & 93 & 67.4 & 39 & 59.1 & 54 & 75.0 & \\
\hline Asian & 40 & 29.0 & 25 & 37.9 & 15 & 20.8 & \\
\hline Other & 5 & 3.6 & 2 & 3.0 & 3 & 4.2 & \\
\hline Nativity & & & & & & & 0.03 \\
\hline U.S. born & 100 & 72.5 & 42 & 63.6 & 58 & 80.6 & \\
\hline Non-U.S. born & 38 & 27.5 & 24 & 36.4 & 14 & 19.4 & \\
\hline Years of experience & & & & & & & 0.14 \\
\hline $0-10$ & 16 & 11.9 & 11 & 16.9 & 5 & 7.2 & \\
\hline $11-20$ & 48 & 35.8 & 18 & 27.7 & 30 & 43.5 & \\
\hline $21-30$ & 39 & 29.1 & 19 & 29.2 & 20 & 29.0 & \\
\hline $31+$ & 31 & 23.1 & 17 & 26.2 & 14 & 20.3 & \\
\hline Recruitment site & & & & & & & 0.06 \\
\hline New York & 33 & 23.9 & 21 & 31.8 & 12 & 16.7 & \\
\hline Michigan & 14 & 10.1 & 8 & 12.1 & 6 & 8.3 & \\
\hline California & 91 & 65.9 & 37 & 56.1 & 54 & 75.0 & \\
\hline Medical school country & & & & & & & 0.002 \\
\hline U.S. medical school & 117 & 85.4 & 49 & 75.4 & 68 & 94.4 & \\
\hline Non-U.S. medical school & 20 & 14.6 & 16 & 24.6 & 4 & 5.6 & \\
\hline Board certification $^{\mathrm{a}}$ & & & & & & & - \\
\hline Medicine & 55 & 39.9 & 55 & 83.3 & - & - & \\
\hline Surgery & 71 & 51.4 & - & - & 71 & 98.6 & \\
\hline Medical oncology & 57 & 41.3 & 57 & 100.0 & - & - & \\
\hline Surgical oncology & 3 & 2.2 & - & - & 3 & 4.2 & \\
\hline Other & 20 & 14.5 & 18 & 27.3 & 2 & 2.8 & \\
\hline \multicolumn{8}{|l|}{ Practice characteristics } \\
\hline Practice type & & & & & & & 0.10 \\
\hline Private & 89 & 65.4 & 38 & 58.5 & 51 & 71.8 & \\
\hline Other & 47 & 34.6 & 27 & 41.5 & 20 & 28.2 & \\
\hline Teaching hospital affiliation & & & & & & & 0.43 \\
\hline Yes & 95 & 69.9 & 44 & 66.7 & 51 & 72.9 & \\
\hline No & 41 & 30.1 & 22 & 33.3 & 19 & 27.1 & \\
\hline NCI-designated cancer center affiliation & & & & & & & 0.42 \\
\hline Yes & 43 & 32.1 & 19 & 28.8 & 24 & 35.3 & \\
\hline \multirow[t]{3}{*}{ No } & 91 & 67.9 & 47 & 71.2 & 44 & 64.7 & \\
\hline & \multicolumn{2}{|c|}{ Total $N=138$} & \multicolumn{2}{|c|}{ Oncologist $N=66$} & \multicolumn{2}{|c|}{ Surgeon $N=72$} & $p$ Value \\
\hline & $\mathrm{M}$ & $\mathrm{SD}$ & $\mathrm{M}$ & SD & $\mathrm{M}$ & SD & \\
\hline $\begin{array}{l}\text { \% Patients evaluating, treating } \\
\text { and following for breast cancer }\end{array}$ & 37.9 & 25.5 & 40.6 & 26.7 & 29.4 & 26.2 & 0.015 \\
\hline $\begin{array}{l}\text { \% New patients in last } 6 \text { months } \\
\text { with breast cancer }\end{array}$ & 30.0 & 26.5 & 39.1 & 27.4 & 20.9 & 21.7 & $<0.001$ \\
\hline$\%$ New patients per week & 13.5 & 10.8 & 7.2 & 3.6 & 19.5 & 11.9 & $<0.001$ \\
\hline \multicolumn{8}{|l|}{ Patient population characteristics } \\
\hline \multicolumn{8}{|l|}{ Race/ethnicity (\%) } \\
\hline White & 51.9 & 21.4 & 53.7 & 22.1 & 49.4 & 21.2 & 0.27 \\
\hline Black & 17.6 & 14.8 & 19.1 & 16.4 & 16.2 & 13.5 & 0.30 \\
\hline Hispanic & 17.3 & 14.6 & 17.2 & 17.1 & 18.3 & 12.6 & 0.68 \\
\hline Asian & 9.8 & 11.5 & 7.5 & 8.9 & 11.7 & 13.3 & 0.04 \\
\hline Other & 2.1 & 4.2 & 2.3 & 4.7 & 2.1 & 3.7 & 0.84 \\
\hline Insurance coverage (\%) & & & & & & & \\
\hline Medicare & 25.7 & 18.8 & 33.9 & 18.0 & 18.9 & 16.8 & $<0.001$ \\
\hline Private insurance & 49.3 & 34.8 & 48.8 & 29.5 & 49.6 & 38.8 & 0.90 \\
\hline Medicaid & 8.7 & 17.7 & 10.8 & 20.8 & 7.0 & 14.7 & 0.25 \\
\hline No insurance & 2.3 & 5.9 & 3.0 & 7.6 & 1.5 & 3.3 & 0.16 \\
\hline Other & 13.6 & 30.5 & 4.9 & 15.5 & 21.8 & 37.8 & 0.002 \\
\hline Language other than English spoken (\%) & & & & & & & \\
\hline Spanish & 12.6 & 14.6 & 12.6 & 17.4 & 13.2 & 12.5 & 0.82 \\
\hline Other & 10.0 & 11.9 & 7.9 & 7.9 & 10.1 & 11.0 & 0.23 \\
\hline
\end{tabular}

a More than one response possible; total $>100 \%$. 
Table 2

Physicians' breast cancer treatment decision related behaviors and attitudes.

\begin{tabular}{|c|c|c|c|c|c|c|c|}
\hline & \multicolumn{2}{|c|}{ Total $N=138$} & \multicolumn{2}{|c|}{ Oncologist $N=66$} & \multicolumn{2}{|c|}{ Surgeon $N=72$} & \multirow[t]{2}{*}{$p$ Value } \\
\hline & $N$ & $\%$ & $N$ & $\%$ & $N$ & $\%$ & \\
\hline \multicolumn{8}{|l|}{ Treatment decision making } \\
\hline Initial consult visit, minutes & & & & & & & 0.021 \\
\hline $0-35$ & 33 & 24.8 & 9 & 13.6 & 24 & 35.8 & \\
\hline $36-45$ & 41 & 30.8 & 21 & 31.8 & 20 & 29.9 & \\
\hline $46-60$ & 51 & 38.3 & 31 & 47.0 & 20 & 29.9 & \\
\hline$>60$ & 8 & 6.0 & 5 & 7.6 & 3 & 4.5 & \\
\hline Visits to make treatment decision & & & & & & & 0.16 \\
\hline 1 & 68 & 51.5 & 30 & 45.5 & 38 & 57.6 & \\
\hline$>1$ & 64 & 48.5 & 36 & 54.5 & 28 & 42.4 & \\
\hline Percent enrolled in clinical trials & & & & & & & 0.07 \\
\hline$\leq 10$ & 84 & 68.9 & 50 & 75.8 & 34 & 60.7 & \\
\hline$>10$ & 38 & 31.1 & 16 & 24.2 & 22 & 39.3 & \\
\hline \multicolumn{8}{|l|}{ Attitudes toward patient involvement in treatment decision-making } \\
\hline Patient-oriented & & & & & & & 0.48 \\
\hline Yes & 60 & 46.2 & 28 & 43.1 & 32 & 49.2 & \\
\hline No & 70 & 53.8 & 37 & 56.9 & 33 & 50.8 & \\
\hline \multicolumn{8}{|l|}{ MD treatment communication behaviors } \\
\hline Discuss the patient's role in the decision-making process & & & & & & & 0.78 \\
\hline Yes & 117 & 88.6 & 59 & 89.4 & 58 & 87.9 & \\
\hline No & 15 & 11.4 & 7 & 10.6 & 8 & 12.1 & \\
\hline Provide a clear statement of what is at issue to clarify what is being decided & & & & & & & 0.65 \\
\hline Yes & 127 & 96.2 & 63 & 95.5 & 64 & 97.0 & \\
\hline No & 5 & 3.8 & 3 & 4.5 & 2 & 3.0 & \\
\hline Discuss alternatives to each treatment including doing nothing at all & & & & & & & 0.18 \\
\hline Yes & 126 & 96.2 & 64 & 98.5 & 62 & 93.9 & \\
\hline No & 5 & 3.8 & 1 & 1.5 & 4 & 6.1 & \\
\hline Explain the potential benefits and risks of treatment and alternatives to treatment & & & & & & & 0.08 \\
\hline Yes & 129 & 97.7 & 66 & 100.0 & 63 & 95.5 & \\
\hline No & 3 & 2.3 & 0 & 0.0 & 3 & 4.5 & \\
\hline Talk about the uncertainties associated with each treatment & & & & & & & 0.15 \\
\hline Yes & 118 & 90.1 & 57 & 86.4 & 61 & 93.8 & \\
\hline No & 13 & 9.9 & 9 & 13.5 & 4 & 6.2 & \\
\hline Assess the patient's understanding of what has been said & & & & & & & 0.54 \\
\hline Yes & 120 & 90.9 & 61 & 92.4 & 59 & 89.4 & \\
\hline No & 12 & 9.1 & 5 & 7.6 & 7 & 10.6 & \\
\hline $\begin{array}{l}\text { Explore the patient's preference and ask for her opinion about the treatment } \\
\text { options discussed }\end{array}$ & & & & & & & 0.31 \\
\hline Yes & 128 & 97.0 & 63 & 95.5 & 65 & 98.5 & \\
\hline No & 4 & 3.0 & 3 & 4.4 & 1 & 1.5 & \\
\hline $\begin{array}{l}\text { Encourage the woman to involve family members and significant others in } \\
\text { treatment decisions }\end{array}$ & & & & & & & 0.23 \\
\hline Yes & 111 & 84.1 & 53 & 80.3 & 58 & 87.9 & \\
\hline No & 21 & 15.9 & 13 & 19.7 & 8 & 12.1 & \\
\hline Provide patients with enough information to make their own treatment decisions & & & & & & & 0.57 \\
\hline Yes & 118 & 89.4 & 58 & 87.9 & 60 & 90.9 & \\
\hline No & 14 & 10.6 & 8 & 12.1 & 6 & 9.1 & \\
\hline Ask patients their opinion about their treatment options & & & & & & & 0.40 \\
\hline Yes & 126 & 95.5 & 64 & 97.0 & 62 & 93.9 & \\
\hline No & 6 & 4.5 & 2 & 3.0 & 4 & 6.1 & \\
\hline \multicolumn{8}{|l|}{ Treatment plan communication barriers } \\
\hline Dealing with the patient's family & & & & & & & 0.055 \\
\hline Not difficult & 63 & 47.7 & 26 & 39.4 & 37 & 56.1 & \\
\hline Difficult & 69 & 52.3 & 40 & 60.6 & 29 & 43.9 & \\
\hline Responding to the patient's emotions & & & & & & & 0.09 \\
\hline Not difficult & 49 & 37.4 & 20 & 30.3 & 29 & 44.6 & \\
\hline Difficult & 82 & 62.6 & 46 & 69.7 & 36 & 55.4 & \\
\hline Being honest without depressing the patient & & & & & & & 0.055 \\
\hline Not difficult & 65 & 49.2 & 27 & 40.9 & 38 & 57.6 & \\
\hline Difficult & 67 & 50.8 & 39 & 59.1 & 28 & 42.4 & \\
\hline Handling your own feelings & & & & & & & $<0.001$ \\
\hline Not difficult & 75 & 56.8 & 26 & 39.4 & 49 & 74.2 & \\
\hline Difficult & 57 & 43.2 & 40 & 60.6 & 17 & 25.8 & \\
\hline Not disclosing poor prognosis at the request of the family & & & & & & & 0.16 \\
\hline Not difficult & 5 & 4.0 & 1 & 1.6 & 4 & 6.5 & \\
\hline Difficult & 121 & 96.0 & 63 & 98.4 & 58 & 93.5 & \\
\hline Not disclosing poor prognosis if the patient doesn't ask & & & & & & & 0.55 \\
\hline Not difficult & 20 & 15.5 & 9 & 13.6 & 11 & 17.5 & \\
\hline Difficult & 109 & 84.5 & 57 & 86.4 & 52 & 82.5 & \\
\hline Giving specific probabilities of treatment not working & & & & & & & 0.94 \\
\hline Not difficult & 39 & 30.0 & 20 & 30.3 & 19 & 29.7 & \\
\hline Difficult & 91 & 70.0 & 46 & 69.7 & 45 & 70.3 & \\
\hline
\end{tabular}


whether or not to undergo chemotherapy and which type of chemotherapy vs. the type of surgery to be done.

Although others have suggested that a physician's motivation to involve patients in the treatment making decision varies by physician cancer site specialty and clinical discipline (oncology vs. surgery), ${ }^{12}$ we found no evidence of such an association in our cohort of breast cancer specialists. Motivation, rather, is complex, quite variable and largely dependent upon the interplay between characteristics of the disease, the patient, and the physician. When a treatment may impact the patient's lifestyle (fertility or sexual function) or self-image (disfiguring surgery), or when disease progresses and the goals of treatment need to be realigned, physicians are more likely to invite the patient into the treatment decision-making process. ${ }^{12}$ The decision to seek patient involvement, however, is tempered by the physician's appraisal of patient characteristics, such as age, cultural background, personality style, cognitive function and anxiety level ${ }^{12,13}$ as well as by the physician's personal attitudes and beliefs surrounding the patient, the treatment, and patient involvement in the treatment decisionmaking process.

During the same office visit when a woman first learns of her breast cancer diagnosis or disease progression, when she is likely experiencing feelings of disbelief, fear, anxiety, and stress, she is oftentimes expected to make a treatment decision. Physician respondents indicated that most treatment decisions are made during this visit, which is generally less than one hour in duration. Nearly unanimously, the physicians in our study, both oncologists and breast surgeons, reported exploring the patient's treatment decision-making preference and probing for her opinions about the treatment options discussed during this crucial visit.

Theoretically, there are three approaches to treatment decisionmaking: paternalistic, where the physician actively makes the decision and the patient assumes a passive role; a consumeroriented model whereby the physician provides information and the patient actively chooses a treatment plan; and an intermediate approach in which the decision is shared between the patient and her physician. ${ }^{14-16}$ Shared decision-making (SDM) is increasingly the standard of care in cancer treatment. ${ }^{17}$ First described in 1982 , SDM is a conceptual framework that supports the discussion of medical treatments and options and evaluates patient preferences for involvement in the treatment decision. Knowledge and concerns exchanged between patients and their physicians provide the physician with an understanding of the patient's values, ideas, and outcome expectations that are used to inform the treatment decision-making process. ${ }^{18}$

Current trends favor SDM and this is reflected in the number of respondents in our study who reported that they provide enough information for a woman to make her own decision, assess the patient's understanding of what has been discussed, and confer with the patient on her preferred role in the decision-making process - all key aspects of SDM. Between 43 and 89\% of women with a breast cancer diagnosis prefer to have an active or collaborative role in their breast cancer care ${ }^{19-22}$ and this preference varies by age and level of education. ${ }^{23,24}$

Incongruity between the physician's perception of the patient's desired level of involvement in the treatment decision and that actually preferred by the patient may have dramatic consequences. $^{19}$ Evidence suggests that approximately $40 \%$ of breast cancer patients do not fulfill their preferred role in their treatment decision $^{4,25}$ and this failure for a patient to achieve her preferred level of control in the treatment decision has been associated with decisional conflict and delay in treatment initiation, decisional regret, poorer quality of life, and decreased treatment satisfaction. ${ }^{26}$

That no significant differences in attitudes or behaviors toward sharing the treatment making decision with their patients were found between surgeons and oncologists is not unexpected. Evidence suggests that achieving the patient's desired level of input to the treatment decision is dependent upon the patient-physician relationship and the quality of patient-physician communication ${ }^{27}$ and these factors transcend physician specialty. In a study of older breast cancer patients and their surgeons, women were more likely to perceive having a treatment choice and to be satisfied with their treatment when there was a high degree of surgeon-initiated communication. $^{28}$ Similarly, oncologists' verbal and non-verbal behaviors influenced the patient-physician communication and were predictive of greater patient involvement in adjuvant breast cancer treatment decisions and lower patient decisional regret. ${ }^{29}$

The results of this study provide insight to the breast cancer treatment decision-making process and the barriers to treatment decisions among breast cancer specialists providing care to a large cohort of breast cancer patients recruited from three sites across the United States. Our study is limited in that we present selfreported behaviors and attitudes that were neither directly observed nor confirmed by patient report. It is possible that physicians may have over-reported behaviors they believed to be socially desirable. In actual practice, physician communication behavior and attitudes are influenced by a host of complex factors including the emotional, social, and personal context of the patient, the complexity and urgency of the decision at hand, the patient's desire to participate in the decision, and the amount of information needed by the patient to feel sufficiently informed to make a treatment decision.

\section{Conclusion}

Our study demonstrates that specialists (breast surgeons and oncologists) involved in the care of a large cohort of women with breast cancer share similar attitudes and beliefs about patient involvement in the treatment decision-making. Despite minor demographic and patient population characteristic differences, these physicians report communicating treatment information to the patient in a manner consistent with shared decision-making, known to enable patients to contribute to their treatment plan.

\section{Ethical approval}

All procedures pertaining to human subject research involved in the conduct of this study were approved by the Institutional Review Board of each recruitment site, and the U.S. Army Medical Research and Materiel Command Office of Research Protection and Human Research Protection Office.

\section{Conflict of interest statement}

The authors declare that they have no conflict of interest.

\section{Acknowledgments}

The authors would like to thank Dr. Olivia S. Fu, Duke University School of Medicine, for her contribution to this work. Supported by a Department of Defense Breast Cancer Center of Excellence Award (BC043120) to Dr. Neugut, National Cancer Institute R01 (CA105274), Department of Defense Center for Biobehavioral Breast Cancer Research to Dr. Kushi, National Cancer Institute R01 (CA100598) to Dr. Ambrosone, and National Cancer Institute R01 (CA124924 and 127617), Department of Defense (DAMD-17-01-10334) to Dr. Bovbjerg, U10 (CA 84131) and K05 (CA96940) to Dr. Mandelblatt. Drs. Hershman and Ambrosone are recipients of funding from the Breast Cancer Research Foundation. Study sponsors had no role in the study design, in the collection, analysis and 
interpretation of data; in the writing of the manuscript; and in the decision to submit the manuscript for publication.

\section{References}

1. Berry DA, Cronin KA, Plevritis SK, Fryback DG, Clarke L, Zelen M, et al. Effect of screening and adjuvant therapy on mortality from breast cancer. $N$ Engl J Med 2005;353:1784-92.

2. Carlson RW, Brown E, Burstein HJ, Gradishar WJ, Hudis CA, Loprinzi C, et al. NCCN task force report: adjuvant therapy for breast cancer. J Natl Compr Cancer Netw 2006;4(Suppl. 1):S1-26.

3. Katz SJ, Morrow M. The challenge of individualizing treatments for patients with breast cancer. J Am Med Assoc 2012;307(13):1379-80.

4. Vogel BA, Helmes AW, Hasenburg A. Concordance between patients' desired and actual decision-making roles in breast cancer care. Psychooncology 2008; 17:182-9.

5. Lantz PM, Janz NK, Fagerlin A, Schwartz K, Liu L, Lakhani I, et al. Satisfaction with surgery outcomes and the decision process in a population-based sample of women with breast cancer. Health Serv Res 2005;40:745-67.

6. Hack TF, Degner LF, Watson P, Sinha L. Do patients benefit from participating in medical decision making? Longitudinal follow-up of women with breast cancer. Psychooncology 2006;15:9-19.

7. Street Jr RL, Voigt B. Patient participation in deciding breast cancer treatment and subsequent quality of life. Med Decis Making 1997;17:298-306.

8. Neugut AI, Hillyer GC, Kushi LH, Lamerato L, Nathanson SD, Ambrosone CB, et al. The Breast Cancer Quality of Care Study (BQUAL): a multi-center study to determine causes for noncompliance with breast cancer adjuvant therapy. Breast J 2012;18:203-13.

9. Liberati A, Apolone G, Nicolucci A, Confalonieri C, Fossati R, Grilli R, et al. The role of attitudes, beliefs, and personal characteristics of Italian physicians in the surgical treatment of early breast cancer. Am J Public Health 1991;81:38-42.

10. Braddock 3rd $\mathrm{CH}$, Edwards $\mathrm{KA}$, Hasenberg NM, Laidley $\mathrm{TL}$, Levinson $\mathrm{W}$. Informed decision making in outpatient practice: time to get back to basics. J Am Med Assoc 1999;282:2313-20.

11. BaileWF,Lenzi R,ParkerPA,Buckman R,Cohen L.Oncologists'attitudestoward and practicesingivingbadnews:anexploratorystudy.JClinOncol2002;20:2189-96.

12. Shepherd HL, Butow PN, Tattersall MHN. Factors which motivate cancer doctors to involve their patients in reaching treatment decisions. Patient Educ Couns 2011;84:229-35.

13. Singh S, Butow P, Charles M, Tattersall MH. Shared decision making in oncology: assessing oncologist behaviour in consultations in which adjuvant therapy is considered after primary surgical treatment. Health Expect 2010;13: 244-57.

14. Emanuel EJ, Emanuel LL. Four models of the physician-patient relationship. I Am Med Assoc 1992;267:2221-6.
15. Charles C, Gafni A, Whelan T. Shared decision-making in the medical encounter: what does it mean? (or it takes at least two to tango). Soc Sci Med 1997; 44:681-92.

16. Stacey D, Samant R, Bennett C. Decision making in oncology: a review of patient decision aids to support patient participation. CA Cancer J Clin 2008;58: 293-304.

17. Makoul G, Clayman ML. An integrative model of shared decision making in medical encounters. Patient Educ Couns 2006;60:301-12.

18. President's commission for the study of ethical problems in medicine and biomedical and behavioral research. Making health care decisions: a report on the ethical and legal implications of informed consent in the patient-practitioner relationship. Washington, DC; 1982.

19. Bruera E, Willey JS, Palmer JL, Rosales M. Treatment decisions for breast carcinoma: patient preferences and physician perceptions. Cancer 2002;94: 2076-80.

20. Hack TF, Pickles T, Ruether JD, Weir L, Bultz BD, Mackey J, et al. Predictors of distress and quality of life in patients undergoing cancer therapy: impact of treatment type and decisional role. Psychooncology 2010;19:606-16.

21. Sabo B, St-Jacques N, Rayson D. The decision-making experience among women diagnosed with stage I and II breast cancer. Breast Cancer Res Treat 2007; 102:51-9.

22. Shields CG, Morrow GR, Griggs J, Mallinger J, Roscoe J, Wade JL, et al. Decisionmaking role preferences of patients receiving adjuvant cancer treatment: a university of Rochester cancer center community clinical oncology program. Support Cancer Ther 2007;1:119-26.

23. Caldon LJ, Walters SJ, Reed MW. Changing trends in the decision-making preferences of women with early breast cancer. Br J Surg 2008;95:312-8.

24. Wallberg B, Michelson H, Nystedt M, Bolund C, Degner LF, Wilking N. Information needs and preferences for participation in treatment decisions among Swedish breast cancer patients. Acta Oncol 2000;39:467-76.

25. Degner LF, Kristjanson LJ, Bowman D, Sloan JA, Carriere KC, O'Neil J, et al. Information needs and decisional preferences in women with breast cancer. J Am Med Assoc 1997;277:1485-92.

26. Maly RC, Leake B, Silliman RA. Breast cancer treatment in older women: impact of the patient-physician interaction. J Am Geriatr Soc 2004;52: 1138-45.

27. Blank T, Graves K, Sepucha K, Llewellyn-Thomas H. Understanding treatment decision making: contexts, commonalities, complexities, and challenges. Ann Behav Med 2006;32:211-7.

28. Liang W, Burnett CB, Rowland JH, Meropol NJ, Eggert L, Hwang Y-T, et al. Communication between physicians and older women with localized breast cancer: implications for treatment and patient satisfaction. J Clin Oncol 2002;20:1008-16.

29. Step MM, Rose JH, Albert JM, Cheruvu VK, Siminoff LA. Modeling patientcentered communication: oncologist relational communication and patient communication involvement in breast cancer adjuvant therapy decisionmaking. Patient Educ Couns 2009;77:369-78. 